\title{
Estimate the prevalence of anemia among unmarried female college students attending nursing college and influence of socio-economic- demographic factors.
}

\author{
Babita
}

\begin{abstract}
:
Introduction: Anemia remains a public health challenge worldwide. Anemia is the most common disorder of blood in the world. According to a survey conducted by NFHS, the prevalence of anemia in young girls aged between 15-24 years is 56\% with higher rates in rural than in urban India. Little is known about anemia among college female students.

Aim: This study aimed to estimate the prevalence of anemia among unmarried female college students attending nursing college and influence of socio-economic- demographic factors. Methodology: Through convenient sampling 320 nursing students studying at Sant Baba Bhag Singh Institute of Nursing were selected. Hb estimation was done using Sahli's method. Baseline information was collected from study subjects through self structured questionnaire.

Results: It was found that as many as $94 \%$ of the female nursing students were suffering from anemia. In regard to severity of anemia, approximately half (51.3\%) were having moderate anemia while (45.3\%) were suffering from mild anemia. Only few (3.3\%) were suffering from severe anemia. Anemia was quite prevalent among B.Sc (96.2\%) as well as GNM (92.5\%) students. The study also depicted the association between prevalence of anemia with selected variables. Chi square was computed. Association of anemia was found statistically significant with H/O chronic disease and irregularity in the menstrual cycle among the study subjects.

Conclusion: Considering the results, it was concluded that anemia is very much prevalent among the nursing students. Thus the investigators recommended the frequent screening of students for presence of anemia and effective services to reduce its prevalence among young adult females.
\end{abstract}

Key Words: Anemia, hemoglobin, young adult female students, sahli's method.

\section{Introduction and Background of the study}

Anemia is a common blood disorder associated with abnormal decrease in number of red blood cell or less than the normal quantity of hemoglobin in the blood. Since hemoglobin carries oxygen from lungs to the capillaries, anemia leads to hypoxia. All humans need oxygen for survival, varying degrees of anemia can have a wide range of clinical consequences. Anemia goes undetermined in many people, and symptoms can be minor. The signs and symptoms can be related to the underlying cause or the anemia itself. Most commonly, people with anemia report feelings of weakness, or fatigue, general malaise, and sometimes poor concentration. They may also report dyspnea (shortness of breath) on exertion. In very severe anemia, the body may compensate for the lack of oxygen-carrying capability of the blood by increasing cardiac output. The patient may have symptoms related to this, such as palpitations, angina (if pre-existing heart disease is present), intermittent claudicating of the legs, and symptoms of heart failure

Anemia remains a serious public health challenge worldwide. According to World health Organization (WHO), an estimated 150 million individuals in the Eastern Mediterranean Region suffer from some type of anemia. There are many causes for anemia; these causes may simply be attributed to acquired or congenital disorders. Iron deficiency anemia is the most frequently acquired nutritional anemia and over 2 billion peoplei.e., nearly one third- throughout the world have iron deficiency anemia.

Most of the anemia prevalence related studies have been performed on infants, children, adolescents and pregnant women. Very few studies concentrated on female college students as the target group. In this study we have focused on college female students, with the purpose of estimating the prevalence of anemia among female collage students and classify anemia severity according to hemoglobin concentration.

\section{Objectives of the study}

1. To assess the prevalence of anemia among young adult female nursing students

2. To compare the prevalence of anemia among B. Sc (N) and GNM nursing students.

3. To find out the association between prevalence of anemia with selected variables. 


\section{Material and Methods}

Research Approach: Descriptive comparative approach

Research Design: Non experimental cross - sectional study design

Setting of the study: Sant Baba Bhag Singh Institute of Nursing

Population: Students of Sant Baba Bhag Singh Institute of Nursing

Sample and Sampling Technique: 320 B.Sc (N) and GNM Students of Sant Baba Bhag Singh Institute of Nursing. Convenient sampling technique was used for the sample selection.

Development of Tool: Tool was divided into two sections

Section 1: Structured questionnaire was developed to collect the background information of the study subjects. Items included in this section were age, residential area, type of family, dietary habits, frequency of taking junk food, monthly income, $\mathrm{H} / \mathrm{O}$ any chronic disease, $\mathrm{H} / \mathrm{O}$ any accident, $\mathrm{H} / \mathrm{O}$ worm infestation, any irregularity in menstrual cycle and duration of menstrual cycle.

Section 2: It involved $\mathrm{Hb}$ estimation of the subjects through Sahli's method. Criteria to indicate and classify severity of anemia were based on ICMR protocol:

\begin{tabular}{|c|c|}
\hline Indicator & Hb $(\mathbf{g m} / \mathbf{d l})$ \\
\hline Non anemic & $\geq 12$ \\
\hline Grade 1 (mild) anemia & $10.0-11.9$ \\
\hline Grade 2 (moderate) anemia & $7.0-9.9$ \\
\hline Grade 3 (severe) anemia & Less than 7 \\
\hline
\end{tabular}

Data Collection procedure: After taking ethical permission from the institute's authorities, data collection was carried out in the month of May - June 2013. Study procedure was explained to the subjects and written consent was also taken.

\section{Analysis of the data}

The analysis of the data was done in accordance with the objectives of the study. Data was analyzed using Descriptive and Inferential statistics through frequencies, percentages and Pearson chi - square test. $p$ value $\leq 0.05,0.01$ and 0.001 was considered significant. SPSS version 15 was used for analysis of the data.

\section{Socio demographic characteristics}

\section{Results}

The socio demographic characteristics of the study subjects revealed that nearly half $(56.6 \%)$ of the study subjects were from age group of $16-19$ years. According to residential area, maximum $(82.5 \%)$ of study subjects belonged to rural area. Regarding type of family, maximum (72.2\%) were from nuclear families. Dietary habits of study subjects revealed that most of the them (81.5\%) were vegetarian. Most of the subjects (64.1\%) had habit of taking junk food once a week. Students were also interviewed regarding H/O chronic diseases, maximum $(95 \%)$ of them responded with not such history. H/O worm infestation also revealed that maximum (94.7\%) didn't have any such kind of history. Maximum (87.2\%) responded that they do not have any irregularity in their menstrual cycle. Maximum (67.2\%) responded that they have 2-4 days duration of menstruation period.

\section{Prevalence of anemia}

Findings related to prevalence of anemia indicated that out of 320 study subjects, maximum (94.4\%) were suffering from anemia. Based upon severity of anemia, out of total 302 anemic students, approximately half $(51.3 \%)$ were having moderate anemia while $(45.3 \%)$ were suffering from mild anemia. Only few (3.3\%) were suffering from severe anemia.

Figure 1: Percentage distribution of nursing students according to prevalence of anemia

$$
\begin{aligned}
& \text { Prevalence of anemia among nursing students } \\
& \qquad \mathbf{N}=\mathbf{3 2 0}
\end{aligned}
$$

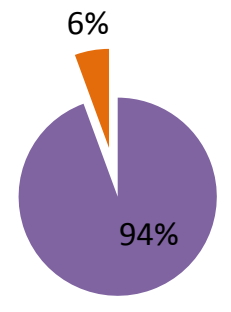

anemic

non anemic 


\section{Comparison of prevalence of anemia among B.Sc (N) and G.N.M. students}

Findings also compared the prevalence of anemia among B.Sc (N) and GNM students. Data revealed that most of the 154(96.2\%) of B.Sc (N) students were suffering from anemia. Prevalence was quite high among GNM students also. Maximum 148 (92.5\%) of them were suffering from anemia. So, prevalence of anemia was found almost equivalent among both the comparison groups.

Figure 2 : Percentage Distribution of Anemic Nursing students according to course of study

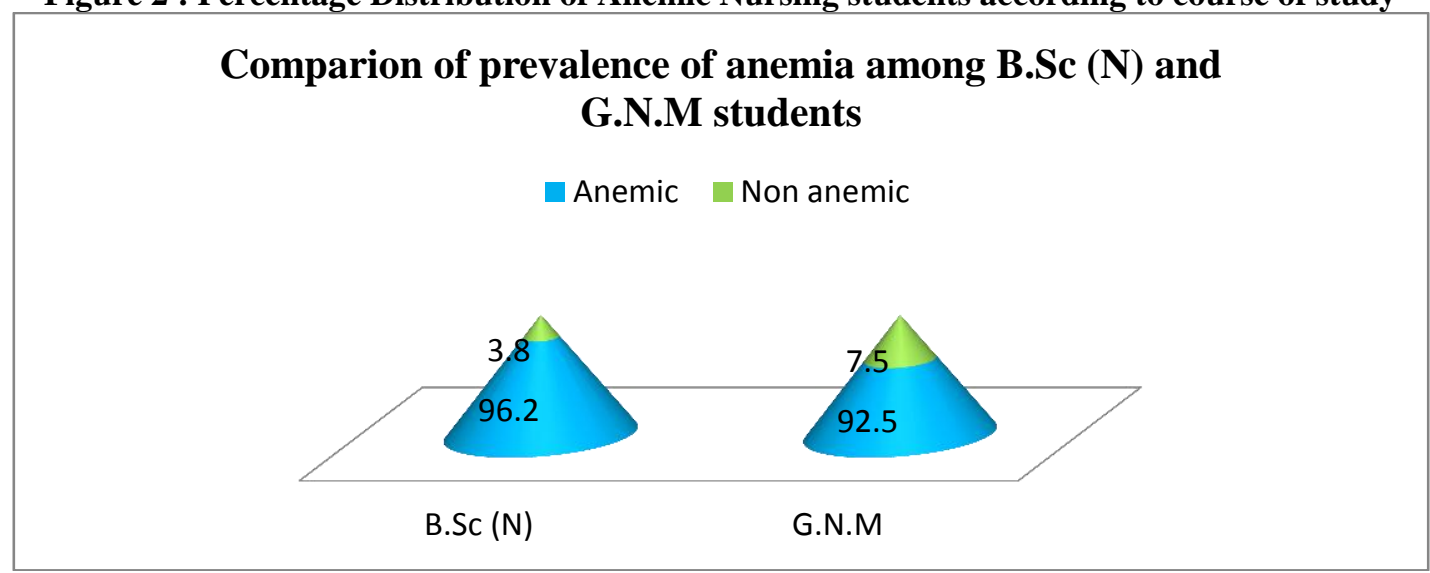

Association of prevalence of anemia with selected variables

Association of prevalence of anemia was find out with selected variables. According to age, most of the anemia $(56.6 \%)$ as well as non anemic (50\%) subjects were from age group of $20-23$ years. Difference was found statistically non significant as p value was 0.553 . Considering the residential area, maximum $(82.5 \%)$ anemic and maximum $(83.3 \%)$ non anemic subjects were belonging to rural area. This difference was also found to be non significant. Association was also found non significant with type of family as maximum of both anemic $(72.2 \%)$ and non anemic $(83.3 \%)$ subjects were from nuclear families. Difference was found in prevalence of anemia according to dietary habits, as anemia was found more $(82.5 \%)$ among vegetarians, but this was also not statistically significant as most of the non anemic $(66.6 \%)$ subjects were also vegetarian. Association with regard to frequency of taking junk food was also found non significant. In regard to family income, association was not found to be significant as maximum of the anemic $(38.7 \%)$ and non anemic $(27.7 \%)$ subjects were having family income between 10001-20000. Association of prevalence of anemia was found highly significant with $\mathrm{H} / \mathrm{O}$ chronic disease, as prevalence was found more among those who were having H/O chronic disease, while no anemia was found among those who didn't have any such kind of history. $\mathrm{p}$ value calculated was 0.000 which is considered highly significant. Similarly difference in prevalence was found according to H/O accident, But it was not statistically significant. Association in regard to worm infestation was also calculated, but found to be non significant as the $\mathrm{p}$ value was more than 0.05. Difference in the prevalence of anemia was found statistically significant in relation to any irregularity in the menstrual cycle. p value was 0.001 which is considered highly significant. Non significant difference was found between prevalence of anemia in association with duration of menstrual cycle.

Table 1: Association of selected variables with prevalence of anemia

\begin{tabular}{|c|c|c|c|c|}
\hline Variable & $\begin{array}{c}\text { Total } \\
\mathbf{N}=\mathbf{3 2 0} \\
\mathbf{f}(\boldsymbol{\%})\end{array}$ & $\begin{array}{c}\text { Anemic } \\
n=302 \\
\mathbf{f}(\%)\end{array}$ & $\begin{array}{c}\text { Non Anemic } \\
\mathbf{n}=\mathbf{1 8} \\
\mathbf{f}(\%)\end{array}$ & p - Value \\
\hline \multicolumn{5}{|l|}{ Age (in years) } \\
\hline $16-19$ & $129(40.3)$ & $120(39.7)$ & $9(50)$ & \multirow[t]{3}{*}{$\mathrm{p}-0.553^{\mathrm{NS}}$} \\
\hline $20-23$ & $181(56.6)$ & $172(56.9)$ & $9(50)$ & \\
\hline More than 23 & $10(3.1)$ & $10(3.3)$ & 00 & \\
\hline \multicolumn{5}{|l|}{ Residential area } \\
\hline Rural & $264(82.5)$ & $249(82.5)$ & $15(83.3)$ & \multirow[t]{2}{*}{$\mathrm{p}-0.924^{\mathrm{NS}}$} \\
\hline Urban & $56(17.5)$ & $53(17.5)$ & $3(16.6)$ & \\
\hline \multicolumn{5}{|l|}{ Type of family } \\
\hline Nuclear & $231(72.2)$ & $216(71.5)$ & $15(83.3)$ & \multirow[t]{3}{*}{$p-0.464^{\mathrm{NS}}$} \\
\hline Joint & $75(23.4)$ & $72(23.8)$ & $3(16.6)$ & \\
\hline Extended & $14(4.4)$ & $14(4.6)$ & 00 & \\
\hline \multicolumn{5}{|l|}{ Dietary habit } \\
\hline Vegetarian & $261(81.5)$ & $249(82.5)$ & $12(66.6)$ & \multirow[t]{3}{*}{$\mathrm{p}-0.076^{\mathrm{NS}}$} \\
\hline Non vegetarian & $49(15.3)$ & $43(14.2)$ & $6(33.3)$ & \\
\hline Eggetarian & $10(3.1)$ & $10(3.3)$ & 00 & \\
\hline \multicolumn{5}{|c|}{ Frequency of taking junk food } \\
\hline Daily & $27(8.4)$ & $25(8.3)$ & $2(11.1)$ & $\mathrm{p}-0.786^{\mathrm{NS}}$ \\
\hline
\end{tabular}


Estimate the prevalence of anemia among unmarried female college students attending nursing

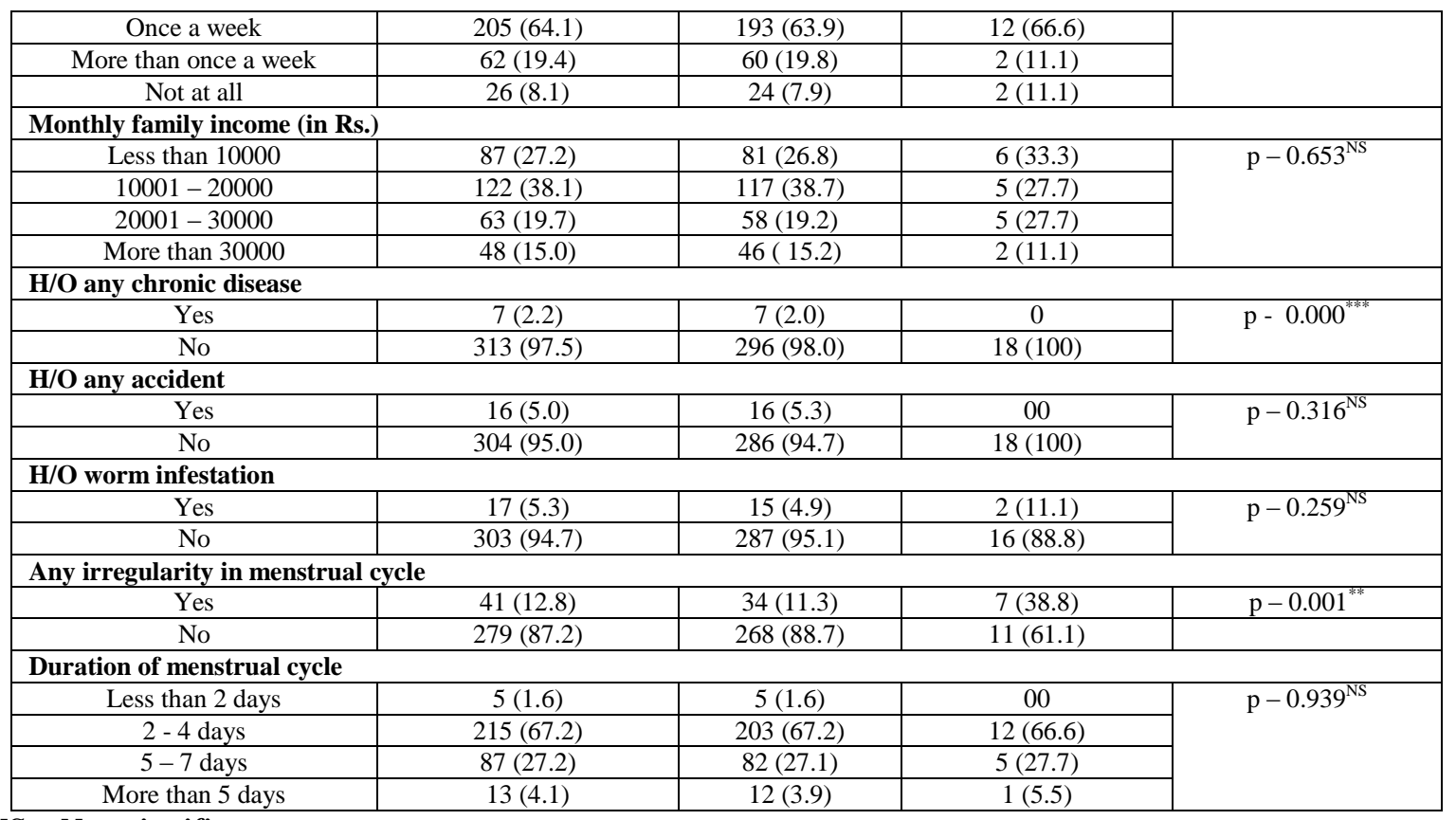

$N S$ - Non significant

** Significant at $p \leq 0.01$

$* * *$ significant at $p \leq 0.001$

\section{Conclusion and Discussion}

Prevalence of anemia among young adult female nursing students was found to be $94.4 \%$. Based upon severity of anemia, out of total 302 anemic students, approximately half $(51.3 \%)$ were having moderate anemia while $(45.3 \%)$ were suffering from mild anemia. Only few $(3.3 \%)$ were suffering from severe anemia. Association of prevalence of anemia was found highly significant with $\mathrm{H} / \mathrm{O}$ chronic disease, as prevalence was found more among those who were having H/O chronic disease. The findings corresponds to an ICMR study by Toteja GS and Singh P who obtained data from 16 districts of 11 states through District Nutrition projects, where prevalence of anemia among adolescent girls has been found to be as high as $90.1 \%$. Similar, studies on anemia prevelence from different states of rural India, reported high prevalence of anemia from 46-98\%. A study carried out among 265 adolescent girls of Amritsar in 2005 by Sharda Sindu also discovered high prevalence $(70-75 \%)$ of anemia including $12.83 \%$ girls who had severe anemia. Taking all this into consideration, young adult female students should be made aware about high prevalence of anemia and regular checking of hemoglobin level should be ensured among them. Studies have also shown successful management of anemia with iron supplementation to adolescent girls which could also be tried out.

\section{References}

[1]. Paul RC. Prevalence of Iron deficiency anemia in India : Results from a nation wide survey. Journal of population and social studies 2010;19(1):2806

[2]. Kaur G, Chhatwal J, Verma M. Prevalence of anemia among urban school children of Punjab. Indian pediatr 1998;35(12):1181-86

[3]. Saratha A, Singh Z, Datta SS et al. Prevalence of anemia among adult female students in a medical teaching institution in Pondicherry. Indian jouranal of maternal and child health 2010 oct- dec ; 12(4)

[4]. Sultan AH. Anemia among female college students attending the university of Sharjah, UAE; Prevalence and classification .J Egypt Public Health Association 2007;82(3\&4)

[5]. Patil MC, Shailja S, Algeer, Veena. A study of knowledge and prevalence of anemia among female students of BldeaA's Shri B M Patil nursing college, Yadavannavar. International journal of current research \& review 2011; 3(11):80 